\title{
Research on Evaluation and Development Strategy of the Dabie Mountains Ecotourism
}

\author{
Ma Yingshuang \\ Business College, Huanggang Normal University \\ Huanggang City, Hubei Province
}

\begin{abstract}
This paper builds the evaluation index system of the Dabie Mountains ecotourism resources from the three dimensions of ecotourism resource conditions, environment quality, and development conditions; it applies analytic hierarchy process to calculate weight of each evaluation index, and based on fuzzy mathematics, employs fuzzy comprehensive evaluation to evaluate resources of three ecotourism scenic areas. All of these validate the feasibility of the evaluation index system, and provide theoretical support and practical guidance to promote the rational and sustainable development of the Dabie Mountain ecotourism resources.
\end{abstract}

Keywords-ecotourism resources; evaluation index; fuzzy comprehensive evaluation; analytic hierarchy process

\section{INTRODUCTION}

Based on the harmony between man and nature as well as coordinated development of economy, society, resources and the environment, not at the expense of resources and the environment, ecotourism emphasizes the protection of natural landscape and biodiversity and maintains sustainable use of resources, with functions of tourism, environmental protection, economy to enrich people, humanistic education and sustainable development (Wang Qiu Ming, 2015). Located in the central part of China, involving 36 counties and 3 cities in Hubei, Henan and Anhui provinces, the Dabie Mountains has important ecological functions. As the restricted development area of the national main functional areas, this region is seriously limited on the choice of industrial development, but ecotourism industry can become one of the best economic and social development paths for this region (Wang Fengge, Yuan Juan, 2014). The ecotourism resource, the material basis for the development of ecotourism industry, is the combination of natural and cultural resources, attracting tourists to "return to nature" ((Wang Qiuming, 2015). The evaluation of ecotourism resources is the prerequisite for the development and protection of ecotourism resources. Its effectiveness lies in scientific selection of evaluation index and objective reflection of regional ecotourism resources by the evaluation system [1]

Based on the evaluation methods of traditional tourism resources and the existing research results, this paper builds the evaluation system of the Dabie Mountains ecotourism resources, and chooses the ecological tourism scenic spots in Huanggang City, Hubei Province, Lu'an City, Anhui Province and Xinyang City, Henan Province as the research area, proposing development countermeasures and suggestions of

Fund Project: Open Project of Dabie Mountains Tourism Economy and Cultural Research Center (03201714703). the Dabie Mountain ecological tourism resources on the foundation of verifying feasibility of the evaluation system.

\section{DEVELOPMENT OF EVALUATION INDEX SYSTEM FOR THE DABIE MOUNTAIN ECOTOURISM}

According to the present situation of the Dabie Mountain ecotourism resources, this paper develops the evaluation index system for Dabie Mountain ecotourism resources on the basis of organic integration of ecotourism resource influencing factors from the perspective of effective development, rational use and maximization of resource value.

\section{A. Development of Evaluation Index System}

Based on regional characteristics of the Dabie Mountain ecotourism resources and analysis of existing research literature, this paper classifies and grades the Dabie Mountain ecotourism resources according to the attributes and domination relations by interviewing tourists and consulting ecotourism practitioners to form the evaluation index system for the Dabie Mountains ecotourism resources. The index system includes three parts of ecotourism resource conditions, environment quality and development conditions. There are 15 specific evaluation indexes in total. Among them, ecotourism resource conditions and environment quality are the basis of ecotourism resources, and the ecotourism development potential is a necessary condition to reflect the value of ecotourism resources.

\section{B. Determination of Evaluation Index Weight}

This paper employs analytic hierarchy process (AHP) as the method of calculating evaluation index weight of the Dabie Mountain ecotourism resources; AHP is a simple and effective tool for evaluating multiple objects under multi-objective and multi-criteria conditions. (Chen Fang, Ma Yingshuang, 2016). Questionnaires of " the Dabie Mountain ecotourism resource evaluation index weight setting" was designed and distributed to 22 tourism industry experts and scholars from April to June in 2017, 19 valid ones recovered. In accordance with the $1 \sim 9$ matrix scale method, evaluation indexes distinguish importance between indicators of the same level. On the basis of the analysis and sorting of questionnaire data, the weight of evaluation index for the general goal has been gained by building the judgment matrix and assigning the values, ordering in single level and whole system, and the consistency check. 
TABLE I.

The Weight of Each Evaluation Index For the General Goal

\begin{tabular}{|c|c|c|c|}
\hline $\begin{array}{c}\text { Objective } \\
\text { level }\end{array}$ & First class index & Second class index & Weight \\
\hline \multirow{13}{*}{$\begin{array}{l}\text { Evaluation of } \\
\text { the Dabie } \\
\text { Mountains } \\
\text { ecotourism } \\
\text { resources }\end{array}$} & \multirow{6}{*}{$\begin{array}{l}\text { Ecotourism resource conditions B1 } \\
\qquad(0.5992)\end{array}$} & Resource rare and unique degree $\mathrm{C} 1$ & 0.1447 \\
\hline & & Biodiversity C2 & 0.1072 \\
\hline & & Ornamental value $\mathrm{C} 3$ & 0.1108 \\
\hline & & Resource reputation C4 & 0.0878 \\
\hline & & Historical and cultural value C5 & 0.0768 \\
\hline & & Research and education value C6 & 0.0719 \\
\hline & \multirow{3}{*}{$\begin{array}{l}\text { Ecotourism environment quality B2 } \\
\qquad(0.2204)\end{array}$} & Air quality C7 & 0.0831 \\
\hline & & Surface water quality C8 & 0.0777 \\
\hline & & Soil quality C9 & 0.0596 \\
\hline & & Location conditions $\mathrm{C} 10$ & 0.0361 \\
\hline & & Traffic conditions C11 & 0.0267 \\
\hline & Ecotourism development conditions & Infrastructure conditions C12 & 0.0327 \\
\hline & $\begin{array}{c}\text { B3 } \\
(01804)\end{array}$ & Appropriate tour period $\mathrm{C} 13$ & 0.0373 \\
\hline \multirow[t]{2}{*}{ A } & & Tourism service level C14 & 0.0242 \\
\hline & & Tourism environment capacity C15 & 0.0234 \\
\hline
\end{tabular}

Among the three first class indexes, the weight of ecotourism resources is 0.5991 , which is higher than the sum of ecotourism environmental quality and development conditions, highlighting a key role of ecotourism resources in ecotourism resources. The weight of resource rare and unique degree in the secondary indexes is 0.1447 , the ornamental value 0.1108 , the biodiversity 0.1072 , and the sum of the three index weight 0.3627 , which reflects the ecotourism characteristic taking the natural ecological environment as the basis [2].

\section{EMPIRICAL TEST ON EVALUATION INDEX SYSTEM FOR THE DABIE MOUNTAINS ECOTOURISM RESOURCE}

\section{A. Empirical Test Methods}

This paper applies fuzzy comprehensive evaluation method to evaluate the status of ecotourism resources in the Dabie Mountains. Based on fuzzy mathematics, the method employs the fuzzy relational synthesis principle to quantify some factors that are unclear and difficult to quantify, comprehensively evaluating classification of things under evaluation from a number of factors (Chen Fang, Ma Yingshuang, 2016). In the evaluation of Dabie Mountain ecotourism resources, due to the cognitive differences of evaluation objects, there is a fuzzy concept of understanding the evaluation index. Therefore, in the comprehensive evaluation of Dabie Mountain ecotourism resources, the application of fuzzy comprehensive evaluation method can objectively evaluate the status of ecotourism resources.

\section{B. Testing Process}

In this paper, three 4A-level scenic spots of Huanggang Bodaofeng scenic area scenic area(H), Liu'an Baimajian scenic area scenic area (L) and Xinyang Jigongshan scenic area (X) in the Dabie Mountains area are selected as the research object, and the fuzzy comprehensive evaluation method is used to analyze ecotourism resources [3]. Evaluation of ecotourism resources uses excellent, good, average, fair, poor as rating levels. Employ the hundred-mark system representing levels, such as poor $(0,20)$, fair $(21,40)$, average $(41,60)$, good $(61$, $80)$, and excellent $(81,100)$.

First of all, invite a total of ten tourism scholars and experts to judge the evaluation indexes of the three ecotourism scenic spots respectively; then, through calculating degree of membership after analyzing and sorting out evaluation results, the fuzzy relation matrix of ecotourism resource evaluation in the three scenic spots can be got, and the fuzzy relation matrix of $\mathrm{H}$ scenic area is shown in Table 2. 
TABLE II. FuZZy RELATION MATRIX FOR EVALUATION ON RED TOURISM RESOURCES OF H SCENIC AREA

\begin{tabular}{|c|c|c|c|c|c|c|c|}
\hline \multirow{2}{*}{$\begin{array}{c}\text { Objective } \\
\text { level }\end{array}$} & \multirow{2}{*}{$\begin{array}{l}\text { First } \\
\text { class } \\
\text { index }\end{array}$} & \multirow{2}{*}{$\begin{array}{l}\text { Second } \\
\text { class } \\
\text { index }\end{array}$} & \multicolumn{5}{|c|}{ Fuzzy relation matrix } \\
\hline & & & $\begin{array}{c}\text { Excellen } \\
\mathrm{t}\end{array}$ & Good & Average & Fair & Poor \\
\hline \multirow{15}{*}{ A } & \multirow{6}{*}{ B1 } & $\mathrm{C} 1$ & 0.8 & 0.2 & 0.0 & 0.0 & 0.0 \\
\hline & & $\mathrm{C} 2$ & 0.7 & 0.1 & 0.2 & 0.0 & 0.0 \\
\hline & & $\mathrm{C} 3$ & 0.8 & 0.1 & 0.1 & 0.0 & 0.0 \\
\hline & & $\mathrm{C} 4$ & 0.9 & 0.0 & 0.1 & 0.0 & 0.0 \\
\hline & & C5 & 0.6 & 0.3 & 0.1 & 0.0 & 0.0 \\
\hline & & C6 & 0.7 & 0.3 & 0.0 & 0.0 & 0.0 \\
\hline & \multirow{3}{*}{ B2 } & C7 & 0.5 & 0.3 & 0.2 & 0.0 & 0.0 \\
\hline & & C8 & 0.6 & 0.3 & 0.1 & 0.0 & 0.0 \\
\hline & & C9 & 0.6 & 0.2 & 0.2 & 0.0 & 0.0 \\
\hline & \multirow{6}{*}{ B3 } & C10 & 0.5 & 0.2 & 0.2 & 0.1 & 0.0 \\
\hline & & $\mathrm{C} 11$ & 0.4 & 0.2 & 0.2 & 0.2 & 0.0 \\
\hline & & $\mathrm{C} 12$ & 0.7 & 0.2 & 0.2 & 0.0 & 0.0 \\
\hline & & $\mathrm{C} 13$ & 0.9 & 0.1 & 0.0 & 0.0 & 0.0 \\
\hline & & C14 & 0.6 & 0.1 & 0.1 & 0.2 & 0.0 \\
\hline & & $\mathrm{C} 15$ & 0.8 & 0.1 & 0.1 & 0.0 & 0.0 \\
\hline
\end{tabular}

Conduct a comprehensive assessment by the order of first low levels and then high ones in calculation, and the fuzzy composite operators is taken as the general matrix product

$$
B=A \circ R=\left[\begin{array}{lll}
0.5992 & 0.2204 & 0.1804
\end{array}\right]\left[\begin{array}{lllll}
0.4549 & 0.0954 & 0.0490 & 0.0000 & 0.0000 \\
0.1239 & 0.0602 & 0.0363 & 0.0000 & 0.0000 \\
0.1184 & 0.0276 & 0.0206 & 0.0138 & 0.0000
\end{array}\right]
$$$$
=\left[\begin{array}{lllll}
0.3212 & 0.0754 & 0.0411 & 0.0025 & 0.0000
\end{array}\right]
$$

After normalization,

$$
B=\left[\begin{array}{lllll}
0.7298 & 0.1712 & 0.0933 & 0.0057 & 0.0000
\end{array}\right]
$$

After the quantization of the result vector $\mathrm{B}$, use the parameter column vector $\mathrm{C}=(90,70,50,30,10)$ to figure out the specific score $\mathrm{P}$ as the final evaluation result, and according to the formula $\mathrm{P}=\mathrm{B} \cdot \mathrm{C}^{\mathrm{T}}, \mathrm{P}_{\mathrm{H}}=82.5$, similarly, $\mathrm{P}_{\mathrm{L}}=$ 79.2 and $\mathrm{P}_{\mathrm{X}}=77.9$.
From the above results, it can be seen that the quantitative score of Huanggang Bo Daofeng scenic area is 82.5 , grade excellent; the scores of Liu'an Baimajian scenic area and Xinyang Jigongshan scenic area are 79.2 and 77.9 respectively, grade good. The evaluation results are recognized by the tourism scholars and experts, conforming to the actual situation of the ecotourism resources of each scenic spot. From the above evaluation, it can be seen that the ecotourism resources of the three scenic spots are of good quality and high reputation, which indicates that the Dabie Mountains has the potential to develop ecotourism, but there are some constraints such as defective infrastructure, low tourism service and management. 


\section{DEVELOPMENT STRATEGY OF THE DABIE MOUNTAIN ECOTOURISM RESOURCE}

\section{A. Cross-regional Cooperation and Scientific Development of Ecotourism Planning}

The development of ecotourism industry is based on natural and cultural environment; scientific and rational ecotourism development plan is the guarantee of healthy and sustainable development of ecotourism industry. Because the Dabie Mountain area is connected with six prefecture-level cities in provinces of Hubei, Anhui and Henan, communication and coordination mechanisms inside the region is required for the formulation of ecotourism planning; respecting and protecting the nature as the principle, ecotourism resource should be exploited without effect on the ecological environment changes. Through regional cooperation, coordinated development of society, economy and ecotourism in the Dabie Mountains can be enhanced by alignment of tourism projects, rational planning of tourism routes, and collaborative management of ecological resources and environment.

\section{B. Improvement of Ecological Environment Protection and Awareness of Natural Conservation}

Emphasis should be placed on ecological and environmental protection in ecotourism resources development, so the government should lead the formulation of ecoenvironmental management rules and regulations, and guide local residents, tourists and scenic staff to participate in the ecological environment protection [4]. Meanwhile, strengthen publicity and education for the masses, tourists and staff, actively create the ecotourism atmosphere for people in the process of understanding nature to enjoy and love the nature, enhance people's awareness of ecological resources protection, stimulate their enthusiasm of the natural environment conservation, and strive to prevent and alleviate ecological problems at the source (Zhu Shirong, 2016).

\section{Shaping of Ecotourism Products with Regional Characteristics}

The Dabie Mountain ecotourism industry development needs not only a good natural ecological environment but also unique ecotourism products with regional cultural characteristics. In the design of tourism products, focus on the theme refining, product diversification, cultural heritage, resource protection and product innovation, endow ecotourism products with rich connotation, help the Dabie Mountains unique village culture, landscape culture and red culture to take root, infuse cultural elements into tourism experience, as well as improve products' additional value, economic and social value through personalized and customized services.

\section{Improvement of the Ecotourism Infrastructure Construction}

Improve mainlines and second lines of transportation for the Dabie Mountain ecotourism scenic spots, promote the transportation convenience of the scenic area, gradually enhance the ecotourism-relevant infrastructure and supporting facilities such as hotels, catering facilities, recreational facilities and so on, and enhance the attractiveness of scenic spots through the creation of quality tourism environment (Fang Tian, et al., 2015). By further optimizing the environmental infrastructure construction and pollutant disposal, enhance environmental quality of the ecotourism scenic spots and its surrounding area, and maintain the ecoenvironmental needs for ecotourism scenic spots [5].

\section{E. Improvement of Ecotourism Personnel Quality}

Tourism quality perceived by tourists is closely related with the quality of tourism personnel. To further enhance the quality of ecotourism services, it is necessary for tourism personnel to be educated about professional ethics and service skills, enhancing their moral norms and skills, effectively solving the current uneven service quality problems. Through the establishment of ecotourism personnel training mechanism, multi-channel cultivation for knowledge about tourism, culture, ecology and management can meet the ecological tourism industry needs of the comprehensive talent and continuously improve the ecotourism service capacity.

\section{CONCLUSION}

The development of ecotourism industry in Dabie Mountains is based on the natural ecological resources of Dabie Mountain area, and the scientific and reasonable evaluation system of Dabie Mountain ecotourism resources is helpful to the development, utilization and protection of ecotourism resources. Based on the development of evaluation index system for Dabie Mountain ecotourism resources, this paper makes an empirical test, and the evaluation results can describe the current situation of ecotourism scenic spots, further showing that the evaluation index system has strong rationality and applicability; the system is of practical significance to evaluate the ecotourism resources of the Dabie Mountains. The exploitation strategy will provide scientific basis and practical guidance for the development and protection of ecotourism resources in the Dabie Mountains.

\section{REFERENCES}

[1] Wang Fengge, Yuan Juan. Research on Development Strategy of the Dabie Mountains Ecotourism Industry [J]. Contemporary Economics, 2014 (20): 24-25.14 (21): 160-161.

[2] Wang Qiuming. Study on the Development of Rural Ecotourism-A Case Study of Benxi County, Liaoning Province [J]. Agricultural Economics, 2015 (4): 15-17

[3] Chen Fang, Ma Yinshuang. Evaluation Index System Development of the Dabie Mountains Red Tourism Resources and Empirical Test [J]. Science \&Technology Information, 2016.

[4] Zhu Shirong. Research on Evaluation and Development Countermeasures of Ecotourism Resources in Sichuan Province [J]. Chinese Journal of Agricultural Resources and Regional Planning, 2016, 37 (8): 218-222.

[5] Fang Tian, Yan Lijiao, Zhao Haiyan.Study on Evaluation System of Ecotourism Resources of Less Developed Counties in South China [J]. Shanghai Environmental Sciences, 2015 (1): 19-25. 